Article

\title{
Can the BestGrid Process Improve Stakeholder Involvement in Electricity Transmission Projects?
}

\section{Nadejda Komendantova ${ }^{1,2, *}$, Marco Vocciante ${ }^{3}$ and Antonella Battaglini ${ }^{4}$}

1 International Institute for Applied Systems Analysis (IIASA), Schlossplatz 1, Laxenburg A-2361, Austria

2 Climate Policy Group, Institute for Environmental Decisions (ETH), Zurich 8092, Switzerland

3 Department of Civil, Chemical and Environmental Engineering, University of Genoa, Genoa 16145, Italy; E-Mail: marco.vocciante@edu.unige.it

4 Potsdam Institute for Climate Impact Research (PIK), Potsdam 14473, Germany;

E-Mail: antonella@pik-potsdam.de

* Author to whom correspondence should be addressed; E-Mail: komendan@iiasa.ac.at;

Tel.: +43-676-83-807-285.

Academic Editor: Vincenzo Dovì

Received: 27 April 2015 / Accepted: 24 August 2015 / Published: 31 August 2015

\begin{abstract}
The European Union has set ambitious targets for deployment of renewable energy sources to reach goals of climate change mitigation and energy security policies. However, the current state of electricity transmission infrastructure is a major bottleneck for further scaling up of renewable energy in the EU. Several thousands of kilometers of new lines have to be constructed and upgraded to accommodate growing volumes of intermittent renewable electricity. In many countries, construction of electricity transmission projects has been delayed for several years due to concerns of local stakeholders. The innovative BESTGRID approach, reported here, brings together transmission system operators (TSOs) and non-governmental organizations (NGOs) to discuss and understand the nature of stakeholder concerns. This paper has three objectives: (1) to understand stakeholder concerns about the deployment of electricity transmission grids in four pilot projects according to five guiding principles: need, transparency, engagement, environment, and impacts on human health as well as benefits; (2) to understand how these principles can be addressed to provide a basis for better decision-making outcomes; and (3) to evaluate the BESTGRID process based on feedback received from stakeholders and the level of participation achieved according to the ladder of Arnstein. This paper goes
\end{abstract}


beyond a discussion of "measures to mitigate opposition" to understand how dialogue between TSOs and the public_-represented mainly by NGOs and policy-makers - might lead to a better decision-making process and more sustainable electricity transmission infrastructure deployment.

Keywords: energy infrastructure projects; transport infrastructure projects; public acceptance and protests; energy transition; electricity grids; renewables

\section{Introduction}

\section{Goals of Climate Change Mitigation and Energy Security Policies}

Climate security goals require a significant reduction of the level of $\mathrm{CO}_{2}$ and other greenhouse gas (GHG) emissions to mitigate the potentially catastrophic risks of climate change [1]. However, anthropogenic GHG emissions continued to increase in the period from 2000 to 2010 with $\mathrm{CO}_{2}$ emissions from fossil fuel combustion and industrial processes contributing about $78 \%$ of total GHG emissions. Energy supply contributes to $47 \%$ of this increase [2]. To achieve climate security goals, emissions should be cut by $50 \%$ globally, and by $80 \%$ in industrialized countries by 2050 [3]. To achieve the mitigation scenario of $450 \mathrm{ppm} \mathrm{CO}_{2}$ by 2100 , reductions of over $90 \%$ of $\mathrm{CO}_{2}$ emissions from energy supply_compared to 2010 levels_are needed in the period between 2040 and 2070 [2]. In 2011, the European Commission published a roadmap to achieve a reduction of GHGs by at least $80 \%$ by 2050 [4]. The roadmap foresees five alternative pathways; for all of these, renewable energy generation plays a significantly stronger role than it does today.

Furthermore, the goals of European energy security policy require that energy generation is restructured toward a greater share of renewable and low carbon sources [5,6]. In October 2014, EU leaders agreed on the 2030 policy framework for climate and energy, which set a GHG reduction target of $40 \%$ compared to 1990 , as well as an increase in the share of renewable energy to at least $27 \%$ of the EU's energy consumption by 2030. Security of energy supply is a high priority in the European policy-making process and the electrical power transmission system is an essential element to achieving this goal. The 2030 framework sets policy targets and different aspects and dimensions of energy security are discussed, from "availability of sufficient supplies at affordable price" [7] to "uninterrupted physical availability on the market of energy products at a price which is affordable to consumers" [8]. According to the International Energy Agency, energy supply is secure if it is adequate, affordable, and reliable [9]. According to [10] energy security has several dimensions, including acceptability and social and environmental stewardship. This aspect of energy security is often associated with unacceptable environmental and social impacts and a significant number of existing scholarly articles on energy security include environmental performance of energy systems in their definition of energy security [11].

Today, the grid is considered to be one of the major barriers to a further increase in renewable energy sources. There are also reasons to believe that to guarantee a reliable and secure electricity supply, construction of a new electricity transmission infrastructure is needed, as well as upgrading the 
existing one. In particular, cross-country interconnectors are required as well as the deployment of smart grid technologies to manage and optimize different energy supply options. According to the Ten-Year Network Development Plan [12], which was developed by the power transmission system operating body ENTSO-E, the construction of roughly extra 52,300 km of high voltage power lines across Europe is required. The extension of electricity grids by only $1.3 \%$ per year will allow for an increase of $3 \%$ of generation capacity and integration of $125 \mathrm{GW}$ of renewable energy sources [13].

Currently, several options to provide the required energy transition are under discussion. These include key elements such as geographically dispersed units, integration of different renewable sources, storage, integration with demand (including adapted demand), and decentralized generation in micro-grids. Additional research about the need for large-scale transmission projects is required, especially in light of the growing importance of distributed or decentralized energy generation (DG) and its consequences for the development of the grid and for high voltage transmission. The term DG applies to electric power generation without distribution networks or on the customer side of the network. Even though DG might have significant benefits, such as reduction of network losses, it could also have additional costs; for example, the protection system may need to be redesigned [14]. Therefore both options, centralized and decentralized energy generation, should be considered.

Currently the process of constructing, extending, and upgrading electricity grids in Europe is extremely slow, and stakeholders question the need for infrastructure projects as well as the assumptions used to determine this need. Claims that new developments are needed to deliver the energy future they favor are also met with skepticism [15-19]. Failing to reach an agreement with local stakeholders on the deployment and siting of projects can cause lengthy and costly delays to the planning process and can even jeopardize the project altogether [20,21]. However, despite substantial efforts in recent years (TEN-E Legislation and national legislation in several EU countries requesting participatory activities) for addressing stakeholders' concerns, scientific evidence of the efficiency of action is still missing.

Taking into account the reality of existing conditions, we examine participatory governance in climate change mitigation and energy security, using existing evidence regarding stakeholders concerns. We formulate and address the following research questions:

- What are the main stakeholder concerns about deployment of electricity transmission grids in Europe?

- What are successful actions to address these concerns?

- What level of participation can be achieved in electricity transmission infrastructure project siting in Europe?

\section{Background}

\subsection{Stakeholders Concerns beyond Not-in-My-Backyard Behavior}

Today, stakeholders' concerns about new transmission line infrastructure are different, compared to when the existing architecture was built in the early 20th century. At that time, infrastructure projects were viewed by many as representing technological progress, providing jobs and contributing to increased levels of social wellbeing [22]. Now transmission line infrastructure is viewed by many as a blight on the landscape and a threat to biodiversity, with negative impacts on property values [23]. 
Furthermore, in past decades a series of technological accidents and environmental disasters negatively influenced stakeholder perceptions and acceptance of new infrastructure [24]. Environmental NGOs have contributed to this discourse by explaining and highlighting the impact that technologies and infrastructure projects have on nature and human health. Today, local citizen groups and NGOs are able to quickly mobilize and articulate opposition towards or support of infrastructure projects [24]. Such a change in views can be partially explained by the distinction proposed by Inglehart (1995) on materialist and post-materialist values; he argued that value priorities shifted significantly in the last decades of the 20th century, from concerns over economic and physical security towards quality of life and freedom of self-expression [25].

It is, therefore, important to understand stakeholders' concerns [20], which are often connected with externalities caused by grid transmission projects, such as the visual, health, and environmental effects as well as perceived loss of property value [26]. These concerns are generally defined as not-in-my-backyard (NIMBY) behavior [27]. The classical understanding of when NIMBYism will arise is when the advantages of the renewable energy sources (RES) projects are perceived to be only at global or national levels, while the impacts of such projects mainly affect only the local population and environment [28].

Pronouncing a local response to new development as NIMBYism can itself be biased, and it is necessary to bear in mind that the NIMBY concept has been frequently questioned, for example by Wolfsink (2012) [29]. In a larger sociopolitical context, NIMBY terminology is frequently used to explain local opposition as selfishness, irrationality, and ignorance. If a researcher applies this concept, they also seem to classify local opposition as such [27]. Often concerns go beyond NIMBY and are about procedural justice, such as the lack of opportunity to express views; this feeling that "voices are not heard" can lead to local opposition [30].

There is also a great difference between accepting deployment of RES in general, and acceptance of the reality of RES generation, an electricity transmission project, or a company on the ground [31]. Often the attitudes of inhabitants towards RES projects can be influenced by factors such as trust in the company, the perceived need for the project, or impacts during and after the construction phase. Opposition to the project can be generated by inhabitants' skepticism towards the company or the authority that wants to develop the project. There is evidence that many protesting inhabitants do so because of their opposition to a company's energy policy or because of the way the project was planned and implemented, rather than specifically opposing infrastructure itself [32]. Inhabitants' skepticism may also be considered as a place-protective action, caused by a reaction to developments that might disrupt existing emotional attachments and threaten place-related identity processes [33]. Public opposition to a project also often focuses on environmental impacts during the installation and construction phases of the project [28].

However, the most frequent concern is local stakeholders questioning the need for a project. In particular, local communities often question the necessity of large-scale infrastructure to address a global problem such as climate change [34]. In the case of electricity transmission projects, stakeholders often want to understand the purpose and possible alternatives-for example, decentralized energy generation [29], which foresees deployment of energy generation near the point of use [35], therefore potentially matching supply with demand. The results of a survey conducted with 
stakeholders at local and national levels do not support the assumption about a gap in responses but rather show the value of adoption of the place-based approach [36].

\subsection{Growing Importance of Public Participation}

According to the Universal Declaration of Human Rights, people have the right to participate in decision-making that affects their lives [37]. There has been no clear evidence of the efficacy of participatory processes in addressing stakeholders' concerns. More specifically, there are multiple ways to design and run a participatory process, but no clear rules to guide stakeholders in choosing the most effective strategies. The traditional view was that decisions regarding technical issues should be concentrated in the hands of experts and scientists [38]. For example, some scholars suggested that stakeholders' involvement in complex decisions may be limited with regards to capacity and knowledge; for example, the ability of stakeholders to understand concepts of "uncertainty" and "variability" might be limited, therefore leaving the leading role in the decision-making process to scientists would be best [39]. However, the need of local stakeholders' participation is being increasingly recognized, as expert knowledge can also be limited, particularly in relation to local knowledge on the ground. Moreover, in some cases, experts disagree among themselves [40] and local knowledge can become decisive for conflict resolution.

Evidence shows that the conceptual approach towards "social acceptance," which dominates in the literature, can be biased and misleading if it is understood as passive agreement to something that one cannot change [41]. In the past, project developers frequently used this understanding of acceptance to assess the efficacy of the participatory process and therefore provide stronger arguments in favor of the project. However, decision-making in participatory governance processes can even result in the cancellation of the project or deliver new alternatives, like construction of alternative infrastructure or use of a different geographic location [22].

The terminology "acceptance" is multi-layered and multi-dimensional. In relation to energy innovation, acceptance was studied by Wüstenhagen et al. [34] and includes a number of potential attitudes towards energy innovation (including RES), such as apathy, passive acceptance, approval, and active support. Such acceptance can take place in policy decision-making, markets, or communities. The definition of "acceptance" by Wüstenhagen is currently used by most researchers to introduce the institutional character of acceptance. It also includes sociopolitical acceptance of new institutional frameworks, for example about how to re-structure decision-making processes towards necessary involvement and participation, as well as institutional shifts in the energy sector away from top-down, centralized, large-scale, fossil fuel-based energy generation, towards inclusive decision-making.

The term "social acceptance" is a multifaceted concept and refers to acceptance of all relevant stakeholders. Otherwise, we refer to acceptance of a certain group as "acceptance by the local public," "acceptance by energy companies," or "acceptance by local governments". When the term "acceptance" applies to laypeople, such as inhabitants of affected communities or citizen of certain countries, we speak about "public opposition" and "public involvement." It should be noted that social acceptance referring to stakeholders in favor of infrastructure has been studied much less frequently [26]. The position of the proponents is not often questioned; those opposing the development are seen as the issue. 
It remains a challenge to understand how the broad concept of energy security, the related need for grid infrastructure, and the complexity of the entire system can be embedded and based on participative democratic practices leading to better outcomes. Research exists on the factors that influence local communities' acceptance of new power lines in light of a transition to low carbon energy generation [41]. However, available evidence is limited, and generally linked to "willingness to pay" research.

Indeed, from the policy perspective, the assessment of the need for large-scale electricity transmission infrastructure is included in scenario frameworks and national power grid plans, which should be consistent with European grid plans and scenarios developed by the grid operator. However, only in a few European countries are these assessments of need the subject of consultation with stakeholders. Furthermore, evidence has shown [41] that research and policy processes should abandon the prescriptive assumption that we know a priori who is "right" about the need for a project. For example, a meta-analysis on existing research about public attitudes to wind power showed that the entire discourse about wind infrastructure siting was dominated by five key assumptions: the majority of the public supports wind power, opposition to wind power is deviant, opponents are ignorant and misinformed, the reason for understanding opposition is to overcome it, and trust is a key. This research showed that trust is indeed a key issue but that a greater trust must also be given to stakeholders and to their knowledge during the decision-making process [42].

In view of the evidence mentioned above, and the need to address increasing public opposition, a number of European countries have developed measures to address citizens' concerns and translated them into legal requirements aimed at improving and defining regulation for stakeholder engagement. Stakeholders' feedback has led to a more careful evaluation of the standards for minimum distances to settlements, clear and robust rules for nature protection and mitigation measures, more transparent planning processes, and a greater ability to influence them [16]. These are all important elements contributing to the legitimacy of the infrastructure siting process and the acceptability of its outcomes.

In order to understand the outcomes of the participatory process, it is necessary to evaluate the process itself. Usually, such a process incorporates certain characteristics that might have an influence on its effectiveness [43]. Most of these elements discussed in the literature are procedural rather than substantive [44], therefore it is easier to evaluate how effective the entire process is, rather than the efficiency of single measures.

One of the most well-known methodologies used to evaluate the participatory process was developed by Arnstein (1969) [45] and Rau (2012) [46]. According to Arnstein's ladder, there are eight elements of participation, classified into three levels (Figure 1). These levels represent the range of intensity in citizen engagement. 


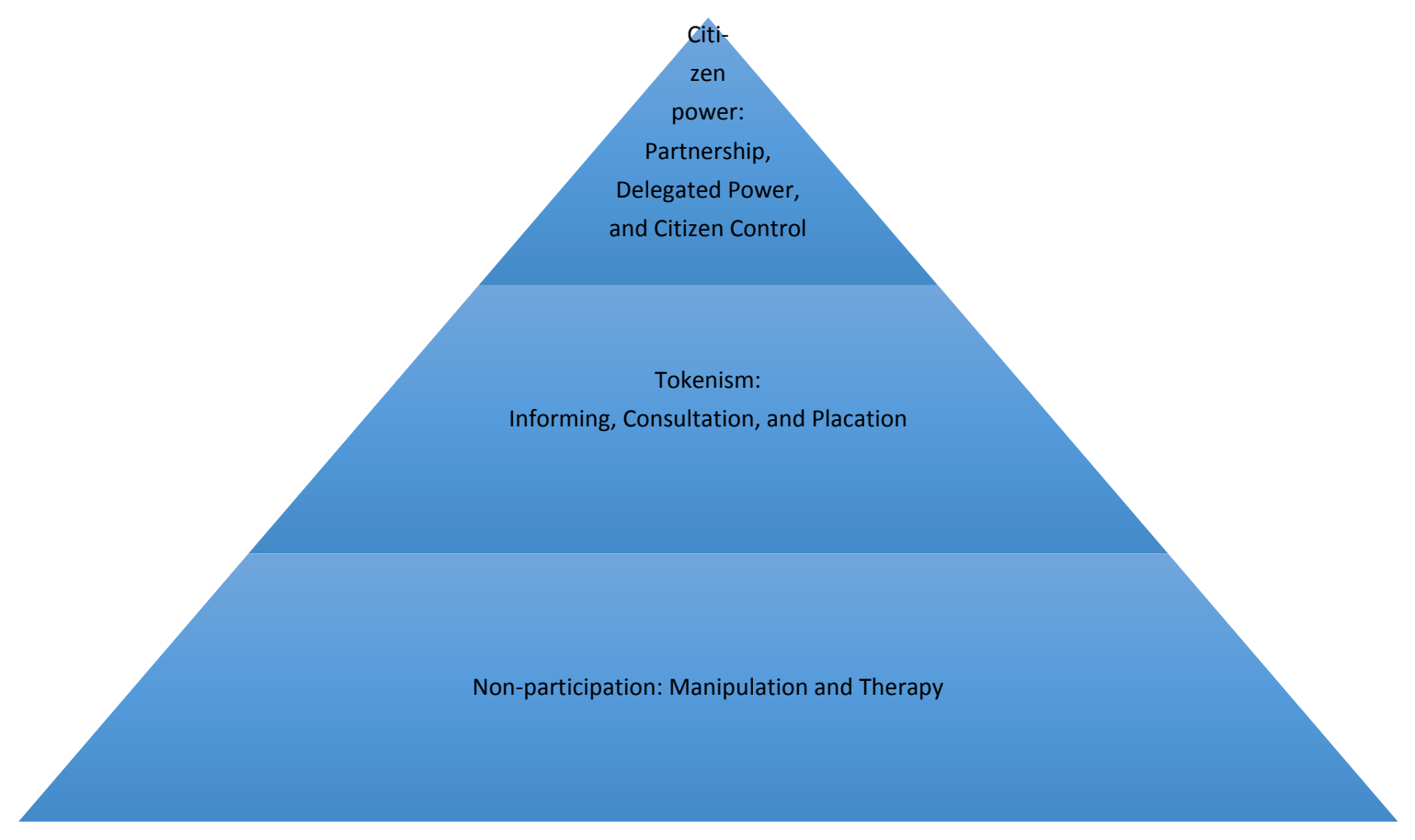

Figure 1. Ladder of participation $[45,46]$.

At the bottom of the ladder, the "non-participation" level includes two very different elements: manipulation and therapy. Manipulation occurs when powerful actors use less powerful and/or disadvantaged population groups to achieve their goals. For example, energy companies in previous centuries sited copper mining infrastructure in developing countries [47]. The therapy element is instead applied to cure a problem or to educate the stakeholders involved. This is a sort of "Decide-Argue-Defend" model that achieves public support largely through public relations for a proposed infrastructure development plan.

The second level, "tokenism," includes informing, consultation, and placation. Informing is one of the steps necessary to legitimize the process. However, this level only allows for a one-way flow of information and participants are not provided with channels for feedback. Public participation is excluded as there is no opportunity for the public to influence the decision-making process. The public is only informed about decisions that have already been made. Unlike in therapy, the intention here is to share information, providing a certain level of transparency about the project and decision-making processes.

At the same level, "consultation" represents the opportunity for the public to provide input during the decision-making process. Local residents are asked about their concerns, and these concerns should be considered by the project developers. Each input also receives a response explaining how it was considered in the final decision. In this phase, a set of tools to collect stakeholders' concerns is suggested and includes data collection via surveys, neighborhood meetings, and public enquiries.

Placation is the next step on the ladder, in which special cooperation, mainly with representatives of stakeholder organizations, is put in place by, for example, setting up advisory roles. In this case, project developers retain the right to judge the legitimacy or feasibility of the advice. At this level stakeholders are invited to participate in the process before any decision is taken and are provided with multiple opportunities to influence the decision-making process. 
The third level is about citizen power and includes partnership, delegated power, and citizen control. In partnerships, the power is redistributed through negotiation between citizens and power holders who share planning and decision-making responsibilities. The have-not, poor, or powerless citizen can negotiate and engage in trade-offs with power holders through, for example, joint committees. Citizen control occurs when citizens handle the entire process of planning, policymaking, and management of the project with no intermediaries. At this level citizens also have the majority of the decision-making seats in the committees, or full managerial power.

\subsection{BESTGRID Approach}

This innovative approach was developed in the framework of the BESTGRID project (www.bestgrid.eu). Its goal is to deploy electricity grids with the minimum possible impact on the environment. The approach also stresses the need to involve stakeholders in the decision-making process as early as possible. This approach was also formulated in the European Grid Declaration (EGD) on Electricity Network Development and Nature Conservation in Europe [48], which defines a set of principles on how to build power lines without harming nature. The Declaration was developed under the guidance of the Renewables Grid Initiative (RGI) secretariat and signed by more than 30 large institutions across Europe.

In 2013 RGI was granted funds within the European Commission's "Intelligent Energy Europe" program to implement the verbal commitments contained in the EGD in real projects on the ground. This resulted in the project BESTGRID - testing better practices. The consortium consists of five TSOs, Elia, TenneT, 50Hertz, National Grid, and Terna; national NGOs Germanwatch and BirdLife International; several local NGOs, such as Bond Beter Leefmilieu Vlaanderen vzw (BBL), Natagora, Fédération Inter-Environnement Wallonie (IEW), DUN, NABU; scientific research institute IIASA; and RGI as coordinator. The BESTGRID project is based on the involvement of stakeholders, such as NGOs, in joint development and implementation of action plans to deal with issues of public acceptance and environmental protection by siting electricity transmission infrastructure. It suggests that the joint efforts of four TSOs, as well as national and local NGOs—-backed by academia — could contribute to a higher level of stakeholder engagement and a better understanding of stakeholders' concerns, using five pilot grid development projects as case studies. NGOs and academic institutions help TSOs improve their stakeholder engagement and environment protection by jointly developing action plans. However, as all pilot projects covered by BESTGRID are still ongoing, it is uncertain to what extent the feedback from stakeholders will influence the outcomes of the projects.

All the BESTGRID pilot projects are high-voltage transmission lines. These are usually operated by one national transmission system operator. Germany is an exception, with four transmission systems operators. There are currently no high-voltage lines operated by third parties in Europe. The only exception is merchant lines-commercial investments that are not regulated assets and not part of remuneration schemes, which foresee a fixed rate of return. Usually merchant lines are leased to grid operators or private actors for specific purposes, so their numbers are very limited. In this paper we discuss high voltage lines in AC and DC up to a voltage level of $380 \mathrm{KW}$.

Superconductor high voltage (SCHV) technologies are potential alternatives and these innovations are already in operation in a number of places, such as Korea and China. Even though this innovation 
is not widely applied, it could be scaled up soon. Indeed, this is an issue of sociopolitical acceptance relevant for high-voltage (HV) transmission, as SCHV might substantially reduce environmental impact, particularly in terms of visibility and electro-magnetic fields. However, the existing regulatory framework in Europe is not yet ready for this innovation, and therefore we do not discuss it in this paper.

Here, we examine the concerns of stakeholders in light of the following five subject areas or guiding principles: need, engagement, transparency, environment, and benefit. These principles were identified in the scientific literature as being crucial to understanding existing support of or opposition to the siting of infrastructure projects $[26,35,42]$.

We have already discussed "need"; the principle "engagement" refers to the need to engage civil society, in particular local communities as well as other interested stakeholders. Engagement is a twoway communication process, which foresees not only the provision of information but also the collection of views, perceptions, and concerns on a particular project and its relation to the broader achievement of the energy transition. Engagement goes beyond simple consultation, which is also a two-way communication process, and implies not only that information is exchanged constantly between public and project developers but also that there is dialogue and negotiation between all parties. This allows for changing of opinions and influences decision-making [39]. Evidence shows that the engagement process should start as early as possible [49]. However, the optimum time for engagement is still unclear because the concept of "as early as possible" can result in a process that starts "too early" to be meaningful to stakeholders, whereas delaying the process could result in stakeholders feeling that they were consulted "too late." Hänlein (2015) described the risk of missing the optimum time for engagement as the "participatory paradox" [50].

The principle "transparency" states that information about the project and decision-making should be transparent at each stage of the process, and the potential for stakeholders to influence the outcomes should be made clear. Transparent participatory processes should be built on discussions and inputs from local stakeholders and involve views and concerns regarding possible alternatives, technologies, impacts, costs, compensations, and benefit-sharing options.

The principle "environment" is based on the fact that, in Europe, environmental protection law is well developed and rather strong. However, the quality and accuracy of implementing environmental protection laws vary substantially from country to country. The value and benefits of fully implementing existing legislations are not fully appreciated across Europe. This principle stresses the need to understand the views and concerns of different stakeholders regarding environmental protection and to address these concerns by planning and constructing new infrastructure. This planning process should also involve feedback from local stakeholders to help avoid harming the environment. Strategic environmental planning also provides an opportunity to consider local stakeholders' concerns related to the possible impacts on human health-such as electro-magnetic fields (EMF) — and to design routes that avoid protected areas and human settlements.

The principle "benefit" investigates the possibilities of providing benefits or compensations to local communities [51] as well as creating additional co-benefits for local communities.

The BESTGRID project provides an opportunity to involve a select group of targeted stakeholders in each pilot project. The process of selecting stakeholders was very different across all pilot projects. In the case of Stevin and Waterloo-Braine's Alleud connections of Elia, the local NGOs BBL and 
Fédération Inter-Environnement Wallonie (IEW) firstly conducted stakeholder mapping to understand who the active stakeholders were. Then the NGOs invited these stakeholders for workshops and round table discussions. In pilot projects by TenneT and 50Hertz, stakeholder events were organized in cooperation with local NGOs and invitations to participate were sent out to a broader range of stakeholders. In the pilot project of National Grid, invitations were sent to a number of stakeholders who already had experience in cooperating with the TSO. These were mainly civil society organizations' representatives and residents of affected communities, the private sector, and authorities (Table 1). BESTGRID also provided funds to enable national and local NGOs, such as Germanwatch and BirdLife, to be directly involved in designing the TSOs' activities on engagement and the environment by providing comments on action plans and guidance on how to address environmental protection and engagement concerns.

Table 1. Realization of the BESTGRID approach in four pilot projects.

\begin{tabular}{|c|c|c|c|c|}
\hline & Elia & TenneT & 50Hertz & National Grid \\
\hline $\begin{array}{l}\text { Need (understanding } \\
\text { needs and concerns of } \\
\text { stakeholders) }\end{array}$ & $\begin{array}{l}\text { Stakeholder mapping. } \\
\text { Interviews to } \\
\text { collect concerns. }\end{array}$ & $\begin{array}{l}\text { Stakeholder mapping. } \\
\text { Survey to collect } \\
\text { concerns. }\end{array}$ & $\begin{array}{l}\text { Stakeholder mapping. } \\
\text { Conducted by public } \\
\text { relations agency. }\end{array}$ & $\begin{array}{l}\text { Stakeholder mapping. } \\
\text { Interviews to } \\
\text { collect concerns. }\end{array}$ \\
\hline Transparency & $\begin{array}{l}\text { Workshop with local } \\
\text { residents to provide } \\
\text { information on } \\
\text { planning. }\end{array}$ & $\begin{array}{l}\text { Public information } \\
\text { events, media } \\
\text { campaign. }\end{array}$ & $\begin{array}{l}\text { Workshops in two } \\
\text { communities to } \\
\text { provide information } \\
\text { on planning. }\end{array}$ & $\begin{array}{l}\text { Mini-workshops in two } \\
\text { communities with civil } \\
\text { society organizations. }\end{array}$ \\
\hline Engagement & $\begin{array}{l}\text { NGOs providing } \\
\text { comments on action } \\
\text { plans. Round table } \\
\text { discussions. }\end{array}$ & $\begin{array}{l}\text { NGOs providing } \\
\text { comments on action } \\
\text { plans. Round table } \\
\text { discussions. }\end{array}$ & $\begin{array}{l}\text { NGOs providing } \\
\text { comments on action } \\
\text { plans. Round table } \\
\text { discussions. }\end{array}$ & $\begin{array}{l}\text { NGOs providing } \\
\text { comments on action } \\
\text { plans. Mini-workshops. }\end{array}$ \\
\hline Environment & $\begin{array}{l}\text { Round table discussion } \\
\text { between TSO and } \\
\text { NGOs to discuss } \\
\text { environmental issues. }\end{array}$ & Information markets. & $\begin{array}{l}\text { Round table discussion } \\
\text { between TSO and } \\
\text { NGOs to discuss } \\
\text { environmental issues. } \\
\text { Media campaign on } \\
\text { EMF, mobile } \\
\text { information office with } \\
\text { EMF measurements. }\end{array}$ & $\begin{array}{l}\text { Mini-workshop } \\
\text { with NGOs. }\end{array}$ \\
\hline $\begin{array}{l}\text { Benefit or } \\
\text { compensation }\end{array}$ & $\begin{array}{l}\text { Not foreseen at the } \\
\text { current stage. }\end{array}$ & $\begin{array}{l}\text { Not foreseen at the } \\
\text { current stage. }\end{array}$ & $\begin{array}{l}\text { Not foreseen at the } \\
\text { current stage. }\end{array}$ & $\begin{array}{l}\text { Not foreseen at the } \\
\text { current stage. }\end{array}$ \\
\hline
\end{tabular}

Questions about the "need" for the project were addressed in a series of workshops with stakeholders, where local residents and representatives of organizations could express their concerns and ask TSOs directly for additional information. Round table discussions were mainly used to address the issues related to the "environment" and "engagement"; environmental NGOs were also able to provide their input and advice on environmental protection during the planning phase of the projects. The TSO 50Hertz also addressed the issue of the EMF and its impact on human health.

The process also included several project meetings where the BESTGRID team members discussed the progress of the action plan's implementation and provided their comments and advice. 
For instance, NGOs advised TSOs on how to approach local residents. The decisions on actions were taken and realized jointly by TSOs and NGOs.

\section{Methodology}

\subsection{Data on Stakeholders' Concerns and Feedback Regarding the BESTGRID Approach}

Data were collected by the joint efforts of the entire BESTGRID team, the International Institute for Applied Systems Analysis (IIASA), and the Renewables Grid Initiative (RGI), as well as national and local NGOs such as Germanwatch, BirdLife, IEW, BBL, DUN, and NABU. IIASA developed data collection protocols, provided input and methodological guidance on different data collection methods-questionnaires, surveys, and feedback forms-and analyzed the results. IIASA, Germanwatch, and RGI provided records of public information events and round table discussions for all pilot projects. Locally involved NGOs such as NABU, DUN, IEW, and BBL provided feedback forms about the BESTGRID project.

In Belgium, IEW and BBL, in cooperation with IIASA, conducted extensive in-depth interviews with local stakeholders. The interviews were based on an open-ended question survey intended to identify concerns of key stakeholders, such as impacts on the environment and human health, as well as land use and energy supply planning issues, for both overhead lines and underground cables. Interviews also provided an opportunity to collect feedback about the BESTGRID project. Interviews lasted approximately two hours and were recorded. Scripts from all the interviews were provided to IIASA in French for analysis of recorded concerns.

As the major goal of the research was to understand stakeholders' concerns, we mainly collected views, feedback, and concerns from organized stakeholders representing civil society, so that we could address the issues of social acceptance or opposition to the projects. All interviews, focus group discussions, and observations were conducted with consideration of ethical issues, such as informed consent. Participants were informed of the goals of the BESTGRID project, and were assured that their concerns, views, and opinions would be the subject of scientific research. Chatham House rules were applied to guarantee the anonymity of participants.

We applied content analysis and data mining to understand which concerns were expressed most frequently. Content analysis is often used for interpretation of documents, which are used for communication processes on infrastructure siting. This method is used to identify evidence from texts such as the frequency of most used words [52]. The material for analysis came from reports about public information events produced by the TSOs and NGOs, as well as from interviews conducted by the NGOs and observations on the site of public information events.

In order to map the interactions between NGOs and TSOs in the pilots of the BESTGRID project, we applied the framework on participation development, as proposed by Arnstein and Rau, to map different levels of stakeholders' participation. We applied this framework to understand how cooperation between TSOs and NGOs could foster public acceptance by minimizing conflicts and, therefore, enhancing the efficiency of the process of deployment of electricity transmission grids. 


\subsection{Case Study Method}

The multiple cases study was used as our research design [53]. The case study allows holistic analysis of events, decisions, projects, policies, institutions, or other systems [54]. This method has been applied in a range of disciplines such as psychology, sociology, economics, political science, geography, and medical science. It has gained popularity recently in testing hypotheses and researching questions that are difficult to answer with existing statistical methods. Focusing on large-scale infrastructure projects, such as the Channel tunnel between Great Britain and France, the case study method helped to identify biases in the decision-making process regarding large-scale infrastructure projects [55]. Other strengths of the method include in-depth analysis, high conceptual validity, an understanding of the context and process as well as the causes of a phenomenon, linking causes and outcomes, and fostering new hypotheses and new research questions [56].

We developed our research protocol according to the methodology of Yin, which includes multiple cases and components of research design such as questions, assumptions, units of analysis within case studies, data, criteria for interpretation of data, and validation. The case-research protocol creates replication logic providing opportunity for generalization and is described in Komendantova et al. [57]. This protocol allowed the various actions by the BESTGRID partners to be transformed into a common framework of actions and guiding principles. This common methodological framework, which categorized actions taken in pilot projects, helps us to understand differences and similarities across the projects.

There are two types of questions related to data collection and stakeholder mapping. The first type relates to all pilots and is therefore called "common to all pilots" questions. The second type relates only to specific actions within certain pilot projects and workshops with local governments (Figure 2). The protocol for data collection is described in Komendantova et al. [58].

We conducted a case study analysis of the following pilot projects: Waterloo-Braine-1'Alleud and Stevin connections by Elia, the Bertikow-Pasewalk connection by 50Hertz, NEMO by National Grid, and SUED.LINK by TenneT. All these projects are designed to serve large-scale, centralized energy generation. It is outside the scope of this paper to discuss alternatives like decentralized generation because researchers seldom have the opportunity to observe the participatory process in "real-world" pilot projects. As these projects did not include alternatives such as decentralized generation, the comparison of received primary data from this research with secondary existing data on alternatives would not be scientifically robust.

Until June 2014, Elia planned to construct a $150 \mathrm{kV}$ onshore underground cable between the two regions of Braine-l'Alleud and Waterloo in the South of Brussels in Wallonia. This project was needed to guarantee a reliable power supply in view of the projected increasing demand from Waterloo. The project should start from the year 2018 and integrate electricity generated by renewable energies. In 2013, the line between Braine-l'Alleud and Waterloo was selected as a pilot project for BESTGRID. The infrastructure project was expected to cover both urban areas and green zones, thus making it an interesting complementary project to other pilots selected to be part of BESTGRID. In June 2014 all actions of Elia were cancelled because the project was postponed for several years. One of the reasons for this was the publication of new data and forecasts from the distribution system operator regarding 
the Waterloo zone, which showed that the growth of electricity consumption in the region was stabilizing, and that a number of requests for connections for wind energy were rejected.

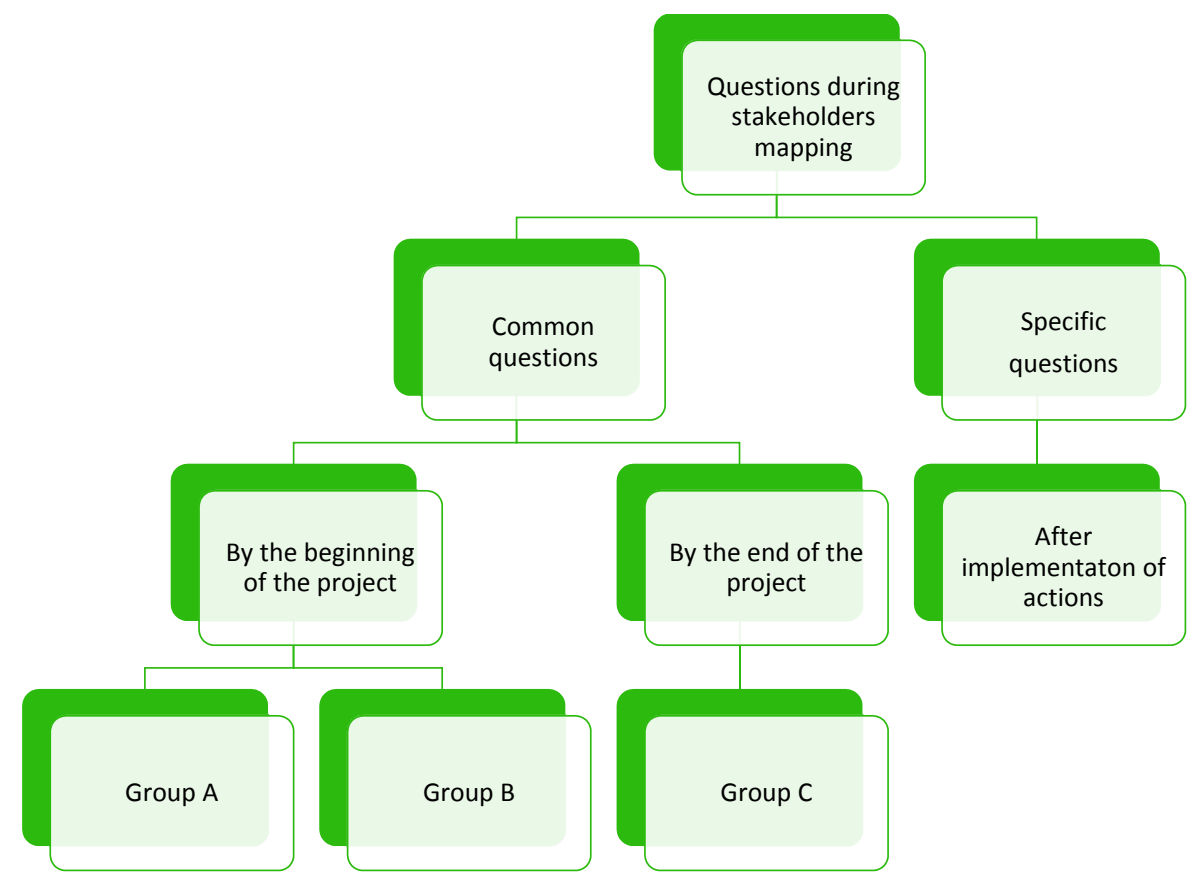

Figure 2. Data collection protocol [58].

The remaining pilot activities were therefore moved to another ongoing project by Elia, the Stevin project, the biggest grid project in Belgium for many years. It will involve the construction of $380 \mathrm{kV}$ electricity lines between Zeebrugge and Zomergem, in the vicinity of Ghent. Out of the $47 \mathrm{~km}$ of transmission lines, $10 \mathrm{~km}$ should be underground. The project will integrate electricity from offshore wind farms, will connect to the NEMO project - the interconnector between the United Kingdom and Belgium - and also contribute to on-shore decentralized energy and harbor development. The project will cross eight communities and two provinces, traversing very densely populated areas as well as natural and landscape protected areas. The fact that it is planned in an area with very dispersed single-family houses and urban settlements is a major challenge.

TenneT, in cooperation with the German TSO TransnetBW, is currently developing the largest energy transmission infrastructure project in Germany, the SUED.LINK. This power transmission line is around $800 \mathrm{~km}$, with a transmission capacity of $4 \mathrm{GW}$, and will deliver electricity generated from wind energy in the North Sea to consumers in central and southern Germany, providing a connection to an area between Wilster in Schleswig-Holstein and Grafenrheinfeld in Bavaria. SUED.LINK is the first line to be constructed using high-voltage direct current (HVDC) lines, which enable large volumes of electricity to be transported over long distances. The $800 \mathrm{~km}$ line is planned to go through dozens of densely populated regions, thus requiring information to be delivered and discussed with thousands of citizens.

50 Hertz is planning a $380 \mathrm{kV}$ overhead line of approximately $29 \mathrm{~km}$ between two communities: Bertikow in Brandenburg and Pasewalk in Mecklenburg-Vorpommern. The project will replace the existing $220 \mathrm{kV}$ line to integrate the growing volumes of electricity from renewable energy sources generated in the Uckermark region and Western Pomerania. Currently, wind turbines in Bertikow are 
generating $330 \mathrm{MW}$, and this is expected to increase to up to $800 \mathrm{MW}$ by 2020 . There are currently 13 alternatives for the corridor, each approximately $1 \mathrm{~km}$ wide, adding up to a total of $11 \mathrm{~km}$. Current plans are that the new lines will be constructed along the existing $220 \mathrm{kV}$ and $110 \mathrm{kV}$ lines from 1950, which will be partly replaced or coupled with the new $380 \mathrm{kV}$ line. The need for the new line was legally set by the German authorities in the year 2013 and it is expected to become operational in 2019.

Under the National Grid pilot, a retrospective evaluation of the consultation and permitting phases for the project is planned. The chosen pilot is the NemoLink project, a joint venture between National Grid and the Elia group constituting a $130 \mathrm{~km}$ interconnection between the United Kingdom and Belgium. The subsea cable will run from Pegwell Bay in the United Kingdom to Zeebrugge in Belgium and will pass through English, French, and Belgian waters.

\section{Results}

The review of actions that were planned or carried out in the pilots showed that different participatory elements were used. We classify these elements according to Arnstein's ladder (Table 2). We also classify the concerns of stakeholders according to five subject areas or guiding principles (need, engagement, environment, transparency, and benefit), which are described in the background section.

Table 1. Actions within four pilot projects, according to Arnstein's Ladder.

\begin{tabular}{|c|c|c|c|c|c|}
\hline & Need & Transparency & Engagement & Environment & Benefit \\
\hline Therapy & $\begin{array}{c}\text { TenneT } \\
\text { media } \\
\text { campaign; } \\
\text { Elia, TenneT, } \\
\text { 50Hertz, and } \\
\text { NG stakeholder } \\
\text { mapping }\end{array}$ & $\begin{array}{c}\text { NG: } \\
\text { mini-workshops } \\
\text { on planning } \\
\text { procedures }\end{array}$ & $\begin{array}{c}\text { NG: } \\
\text { mini-workshops } \\
\text { where } \\
\text { stakeholders } \\
\text { who had } \\
\text { experience of } \\
\text { cooperation } \\
\text { with the TSO } \\
\text { were invited }\end{array}$ & $\begin{array}{c}\text { 50Hertz: } \\
\text { video about } \\
\text { EMF }\end{array}$ & No \\
\hline Information & $\begin{array}{c}\text { Elia and } \\
50 \text { Hertz: } \\
\text { workshops with } \\
\text { local residents } \\
\text { on the need of } \\
\text { the project }\end{array}$ & $\begin{array}{l}\text { Elia and } \\
50 \text { Hertz: } \\
\text { workshops with } \\
\text { local residents } \\
\text { on the details of } \\
\text { planning; } \\
\text { TenneT: public } \\
\text { information } \\
\text { campaign }\end{array}$ & $\begin{array}{c}\text { TenneT, Elia, } \\
\text { and 50Hertz: } \\
\text { public } \\
\text { information } \\
\text { events providing } \\
\text { information to } \\
\text { organized } \\
\text { stakeholders } \\
\text { about } \\
\text { engagement } \\
\text { opportunities }\end{array}$ & $\begin{array}{c}\text { NG: } \\
\text { mini-workshops } \\
\text { on the impacts } \\
\text { on the } \\
\text { environment; } \\
50 \text { Hertz: } \\
\text { mobile office } \\
\text { information tour } \\
\text { on impacts of } \\
\text { EMFs }\end{array}$ & $\begin{array}{l}\text { Elia, } 50 \text { Hertz, } \\
\text { TenneT, and } \\
\text { NG: workshops } \\
\text { and round table } \\
\text { discussions on } \\
\text { the benefits of } \\
\text { the project }\end{array}$ \\
\hline
\end{tabular}


Table 2. Cont.

\begin{tabular}{|c|c|c|c|c|c|}
\hline & Need & Transparency & Engagement & Environment & Benefit \\
\hline Consultation & $\begin{array}{l}\text { Elia: interviews } \\
\text { to collect } \\
\text { stakeholder } \\
\text { concerns; } \\
\text { TenneT: } \\
\text { surveys to } \\
\text { collect concerns } \\
\text { and feedback on } \\
\text { public } \\
\text { information } \\
\text { events }\end{array}$ & $\begin{array}{l}\text { TenneT: public } \\
\text { information } \\
\text { markets }\end{array}$ & $\begin{array}{l}\text { Elia, 50Hertz, } \\
\text { NG, and } \\
\text { TenneT: } \\
\text { partnership with } \\
\text { Germanwatch } \\
\text { on stakeholder } \\
\text { engagement }\end{array}$ & $\begin{array}{l}50 \text { Hertz and } \\
\text { Elia: round table } \\
\text { discussions on } \\
\text { impacts on the } \\
\text { environment }\end{array}$ & No \\
\hline Placation & No & $\begin{array}{c}50 \text { Hertz and } \\
\text { NG: partnership } \\
\text { with } \\
\text { Germanwatch } \\
\text { on action plans } \\
\text { to increase } \\
\text { transparency }\end{array}$ & No & $\begin{array}{c}50 \text { Hertz and } \\
\text { NG: partnership } \\
\text { with BirdLife on } \\
\text { environmental } \\
\text { protection }\end{array}$ & No \\
\hline Partnership & No & $\begin{array}{c}\text { Elia and } \\
\text { TenneT: } \\
\text { partnership with } \\
\text { Germanwatch } \\
\text { on action plans } \\
\text { to increase } \\
\text { transparency }\end{array}$ & No & $\begin{array}{l}\text { Elia and } \\
\text { TenneT: } \\
\text { partnership with } \\
\text { BirdLife on } \\
\text { environmental } \\
\text { protection }\end{array}$ & No \\
\hline Delegation & No & No & No & No & No \\
\hline Control & No & No & No & No & No \\
\hline
\end{tabular}

This table shows that almost all actions foreseen by TSOs fall in the middle of Arnstein's ladder, varying from therapy to information and consultation. No manipulation was found. Even though selection of the participating group of stakeholders by the project developers is defined in the literature as manipulation [55], we still consider the mini-workshops of the National Grid as a higher level of participation because national NGOs had a chance to comment on the process of organization of these workshops. Most of the TSOs' actions are at the levels of information and consultation. In our view, the info markets introduced by TenneT can be considered to be a mixture of information and consultation. They allow project developers to introduce themselves to stakeholders and to encourage an open dialogue. Round table discussions and mini-workshops allow a smaller number of participants to discuss specific issues. Independent observers recorded stakeholders' feedback and the TSOs replied to concerns raised by stakeholders.

Table 2 also shows the level of participation needed to address each guiding principle. For instance, therapy would entail providing information to address the perception of risks, such as impacts on human health, while the information level could address all five guiding principles. The higher we climb the ladder, the lower the number of guiding principles addressed by BESTGRID. For instance, 
at the partnership level, only the environment and transparency principles were addressed through cooperation between national and local NGOs and TSOs.

During the planning procedures, round table discussions, and workshops, NGOs provided input into the planning of infrastructure. This feedback corresponds to a level of consultation and placation where NGOs can play an advisory role but TSOs retain the right to judge the legitimacy or feasibility of the advice received. We attribute the efforts to settle action plans in cooperation between NGOs and TSOs at the level of placation for the pilots of National Grid and 50Hertz because decisions were frequently taken without involving NGOs or informing them about the decisions already taken. The cooperation between NGOs and two other TSOs, Elia and TenneT, allowed for more extensive feedback and a higher level of participation, reaching the level of partnership between TSOs and NGOs by jointly developing the action plans. However, this consultation was also restricted as the options and issues to be raised were defined by the developers and authorities. Finally, a key factor was that the need for the projects was identified by the developers and authorities, who were not prepared to discuss alternatives.

Existing evidence suggests that the middle level of Arnstein's ladder is the most frequent level of stakeholders' participation in developed economies. However, only consultation, involvement, or collaboration with stakeholders occurs at this level. This does not equate to full participation, but rather suggests tokenism as stakeholders cannot influence decisions.

The BESTGRID approach goes beyond this level, as it allows for a stronger and systematic collaboration between TSOs and NGOs. This can be considered an innovative approach because the two groups are involved in the same project, their collaboration is voluntary, based on the recognition of common interests and respect of each other priorities, and it is guided by an independent organization, in our case, the Renewables Grid Initiative. The NGOs Germanwatch and BirdLife actively commented on plans and provided the TSOs with guidance on the design and implementation of actions relating to public acceptance and environmental protection. These recommendations stimulated TSOs to implement some extra measures not requested by legislation. For instance, the following recommended participation and consultation tools were implemented: info-markets, mobile bus tours, and roundtable discussions. The feedback from participants showed that info-markets and information events were successful in demonstrating the need for the project to the public and organized stakeholders. The roundtable discussions helped to collect feedback and new suggestions on actions to protect the environment.

Existing evidence regarding the process of siting electricity transmission projects in other countries corresponds with our results. For example, in its review of ongoing infrastructure projects, the U.S. Environmental Protection Agency came to the conclusion that public participation may occur at multiple levels and at different stages of the project, and that different stakeholders may choose to engage at different levels. Generally, a higher level of participation requires more effort from both project developers and stakeholders, and therefore attracts fewer stakeholders. In light of this, we mapped stakeholders and their level of engagement across the four pilot projects as well as the different levels of Arnstein's ladder (Table 3). 
Table 2. Stakeholders in four pilot projects.

\begin{tabular}{|c|c|c|c|c|}
\hline & Therapy & Information & Consultation & Cooperation \\
\hline Elia & & Local residents & $\begin{array}{l}\text { Environmental } \\
\text { stakeholders }\end{array}$ & $\begin{array}{c}\text { IEW, BBL, } \\
\text { Germanwatch } \\
\text { BirdLife }\end{array}$ \\
\hline 50 Hertz & Local residents & Local residents, NGOs & $\begin{array}{l}\text { Environmental and } \\
\text { critical stakeholders }\end{array}$ & $\begin{array}{c}\text { DUH, NABU, } \\
\text { Natagora, } \\
\text { Germanwatch, } \\
\text { BirdLife }\end{array}$ \\
\hline TenneT & Local residents & Local residents & $\begin{array}{l}\text { Environmental and } \\
\text { critical stakeholders }\end{array}$ & $\begin{array}{l}\text { Germanwatch, } \\
\text { BirdLife }\end{array}$ \\
\hline National Grid & $\begin{array}{l}\text { Established group } \\
\text { of stakeholders }\end{array}$ & Local residents & $\begin{array}{c}\text { Environmental } \\
\text { stakeholders }\end{array}$ & $\begin{array}{c}\text { Germanwatch } \\
\text { BirdLife }\end{array}$ \\
\hline
\end{tabular}

Content analysis of reports, protocols, and interviews containing the concerns of both organized stakeholders and laypeople, showed that the guiding principle "need" was one of the most questioned principles in all three pilots and was mentioned 235 times. "Environment" was also discussed often (mentioned 149 times) as well as "transparency" (mentioned 125 times). The guiding principles "benefit" and "engagement" were raised significantly less frequently (45 and 53 times, respectively). Figure 3 shows the patterns of concerns regarding guiding principles.

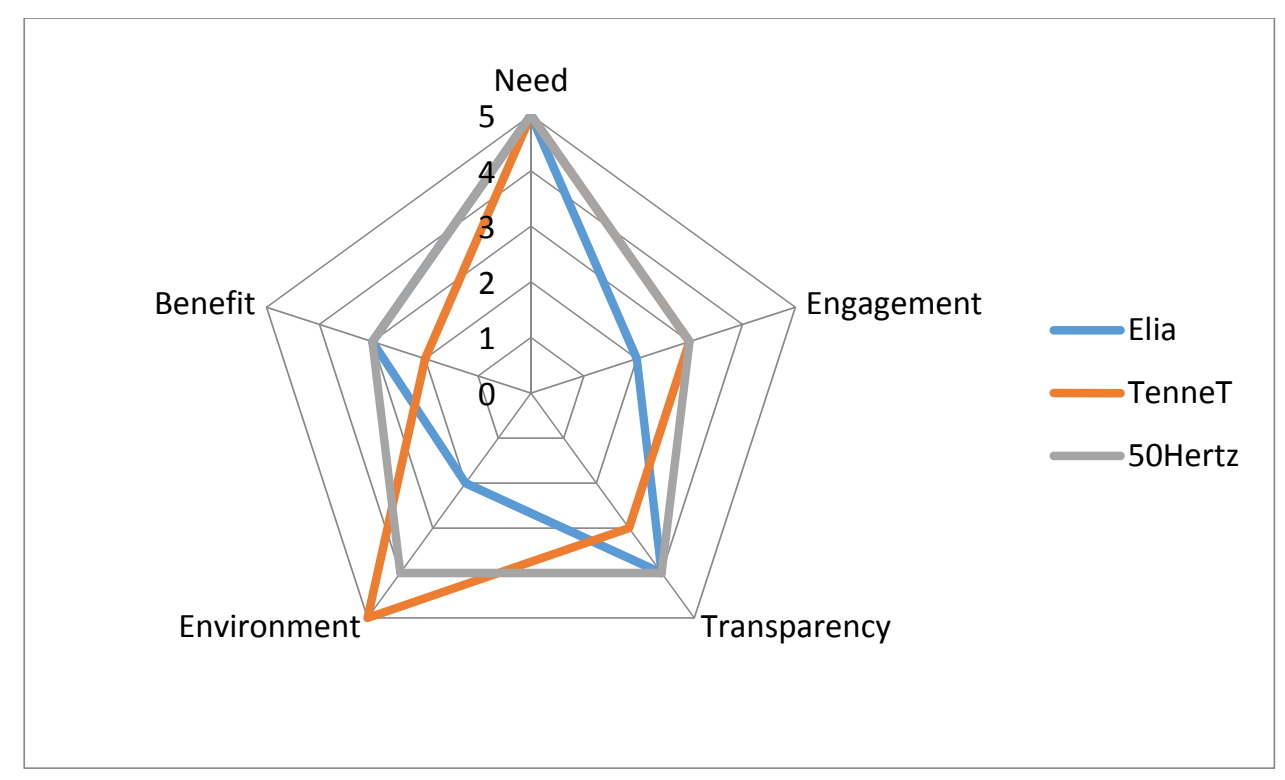

Figure 3. Concerns according to five guiding principles.

The need for the projects was often unclear to local inhabitants. Generally speaking, they questioned why the projects were needed, in light of available alternatives such as decentralized energy generation and efficiency measures. They also requested clarification regarding factors influencing discussion about the need of the project, such as future energy demand in the region, population dynamics, migration of industries, energy efficiency measures, and options for decentralized energy generation. 
"Environment" was the second most heatedly discussed principle and it raised many very specific concerns. In the case of the Elia project, concerns were limited and mainly pertained to the impacts during the construction period. This is largely due to the location and the relative size of the Elia project. In the TenneT pilot, the impacts on the environment, including those on nature and ecosystems, were fiercely debated, as well as the visibility impacts on the landscape and impacts of EMF on human health. In this case, stakeholders perceived the direct involvement of environmental NGOs very positively, but concerns about landscape impacts and EMFs were only partly addressed.

The BESTGRID actions allowed stakeholder concerns to be heard and understood. BESTGRID also provided the opportunity for NGOs to advise on how to deal with the concerns raised, including the provision of detailed information on the impacts of EMF, conducting EMF measurements, and involving independent experts to talk about the risks of EMFs. These recommendations were partly implemented by $50 \mathrm{Hertz}$ during the mobile information tour and round table discussions. The recommendations on visibility effects included the possibilities of merging old and new lines or applying new design options to the construction of pylons in consultation with stakeholders using 3D visualization tools. Additional research is needed in many cases to better understand whether these measures can reduce social opposition to infrastructure projects.

The principle "transparency" was frequently discussed. Stakeholders requested clear information as they had doubts regarding the level of transparency of information and, in particular, questioned the sources of electricity to be fed into the grid. In all pilots, stakeholders requested more information about the preferred corridor, the criteria used for its selection, and the details of the planning process.

Transparency of information is often connected with the issue of trust in the companies, officials, or sources of information. During the public information events, concerns about the trustworthiness of information were raised several times, especially with respect to published information or experts engaged by TSOs to report about contested issues, such as the impacts of EMF. During the focus group discussions, the issue of trust also appeared several times, namely regarding the sources of information. Public authorities and academics were regarded as the most trustworthy source of information about the risks or the need for the project.

The guiding principle "benefits" was least frequently discussed. The major concerns were co-benefits, such as the modernization of roads in the region during construction, and compensation to separate groups of stakeholders such as landowners or to the entire community.

The principle "engagement" did not attract much attention among stakeholders. Generally, they did not believe that they would have an opportunity to engage, and therefore questioned the value of engagement as a result of previous experience. Stakeholders reported their doubts that their voices would be considered and complained that information regarding the different types of possible participation was limited (Table 4).

The BESTGRID approach has not led to a higher level of public participation such as delegation or citizen control. Evidence shows that achieving these levels is possible; for example, citizen control proved to be successful in the implementation of some wind projects where public resistance turned into public support [59].

However, the approach developed and deployed in BESTGRID can be regarded as an improvement in the quality of engagement and an important learning experience for all participants. Despite the fact that the information provided by TSOs on the need for specific electricity grids, projects for supporting 
the energy transition, and energy security significantly contributed to open discussions about the need for the electricity transmission projects, it remains questionable whether TSOs should have to provide such information or whether this should be the responsibility of other stakeholders, such as regulators, policy-makers, or civil society itself.

Table 3. Concerns according guiding principles.

\begin{tabular}{|c|c|c|c|}
\hline Guiding Principle & Elia (Underground Cable) & TenneT & 50Hertz \\
\hline Need & $\begin{array}{l}\text { Unclear need as it is not certain } \\
\text { if energy consumption in the } \\
\text { region will be growing }\end{array}$ & $\begin{array}{c}\text { Unclear need because of } \\
\text { decentralized } \\
\text { generation options }\end{array}$ & $\begin{array}{l}\text { Unclear need for } \\
\text { the project }\end{array}$ \\
\hline Engagement & $\begin{array}{l}\text { Optimum time for engagement, } \\
\text { perception that voices will not } \\
\text { be heard }\end{array}$ & $\begin{array}{l}\text { Place of public information } \\
\text { events, where anybody could } \\
\text { pass by, not only already } \\
\text { informed stakeholders }\end{array}$ & $\begin{array}{l}\text { Information about } \\
\text { who will be involved } \\
\text { in the discussions } \\
\text { on the project }\end{array}$ \\
\hline Transparency & $\begin{array}{c}\text { Planned corridor, sources } \\
\text { of electricity }\end{array}$ & $\begin{array}{c}\text { Criteria of selecting priority } \\
\text { corridor, sources } \\
\text { of electricity }\end{array}$ & $\begin{array}{c}\text { Planning procedures, } \\
\text { source of electricity, } \\
\text { EMFs }\end{array}$ \\
\hline Environment & $\begin{array}{l}\text { Impacts of construction, } \\
\text { visibility effects }\end{array}$ & $\begin{array}{l}\text { Visibility impacts, security of } \\
\text { transmission system, impacts } \\
\text { from EMFs }\end{array}$ & $\begin{array}{l}\text { Impacts on } \\
\text { environment, visibility } \\
\text { impacts, impacts from } \\
\text { EMFs }\end{array}$ \\
\hline Benefit & $\begin{array}{l}\text { Modernization of routes during } \\
\text { construction period, jobs, } \\
\text { and impulses for } \\
\text { socioeconomic development }\end{array}$ & & $\begin{array}{l}\text { Compensation to } \\
\text { land-owners, } \\
\text { compensation } \\
\text { to environment }\end{array}$ \\
\hline
\end{tabular}

For the Elia and 50Hertz pilot projects, we also collected feedback on the usefulness of the approach and the activities that ran as part of BESTGRID. The responses generally indicated a high level of interest and satisfaction from local stakeholders. Organized stakeholders in particular, rather than laypeople, were positive about the participatory process. Some mentioned that such participatory processes would require more time but could indeed provide stronger arguments in favor of projects, and therefore save time at a later stage of the permitting procedures. One interesting recommendation from both experts and laypeople was that ideas and propositions for possible corridor alternatives should be systematically collected.

In the case of Elia, stakeholder organizations, such as public authorities and NGOs, declared that the project helped to raise awareness and increase knowledge levels (87\% of respondents). For the majority of stakeholders $(82 \%)$, their interest in BESTGRID and the project increased after the public information events. Respondents appreciated the content discussed at the events, with $45 \%$ of participants judging it to be very good and 55\% good. However, generally speaking, it seems that additional information is desired. Overall, 35\% declared their satisfaction with the information provided during the workshop, but $65 \%$ of participants indicated their wish for more information. It is important to note that, according to stakeholders, more information is required from local authorities about the details of the planned corridor and its alternatives, the possibilities for participation and 
engagement, the planning process, and the expected benefits generated by the project for affected communities.

In the case of $50 \mathrm{Hertz}$, evaluation of the feedback from stakeholders showed that $85 \%$ of all participants considered the round table discussions interesting and that they provided stakeholders with important information and suggestions. A total of $80 \%$ of participants thought that the local stakeholders and experts from the scientific field who participated in discussions had sufficient expertise and provided valuable input, and $75 \%$ of all participants will definitely consider participating in follow-up events. However, participants noticed that the value of round table discussions is limited because it is more difficult to reach a broad range of interested stakeholders through such a forum.

\section{Discussion}

Our results showed that concerns about the need for a project, issues of visibility, and impacts on human health as well as transparency of information about planning procedures are more relevant than concerns about compensations or benefits from the projects. These results correspond with existing evidence. For example, Porsius et al. (2014) [60] suggested that perceptions about the impacts from EMF on human health are among the greatest concerns regarding the deployment of electricity transmission grids. The results of their study showed an increase in non-specific health complaints and attribution of these complaints to a new power line in a residential area. Tempesta et al. (2014) [61] found that overhead transmission lines have major impacts on how people perceive landscape aesthetics; a pylon occupying even a minor fraction of the view can spoil the look of the landscape. Their study showed that the social benefits of burying high voltage power lines would exceed the costs in some parts of the country, such as the mountains, where the willingness of population to pay, per kilometer of power line eliminated, is higher. Elliott and Wadley (2012), who studied homeowners' perceptions of high-voltage overhead transmission lines, also identified pylon design, health effects, and visual and noise impacts as being among the major concerns [62].

In the current study, many stakeholders raised concerns about the need for large-scale transmission projects in light of available alternatives. Several alternatives were discussed such as decentralized and distributed energy generation, energy efficiency measures, and alternative routings for the transmission lines. A more detailed discussion about centralized versus decentralized or distributed energy generation was out of the scope of this research; however, this would be a very interesting topic for follow-up research. This is a very complex issue with many pros and cons for both options and several existing studies try to understand the advantages and disadvantages of both. Such research would also involve the very complex question of to what extent stakeholders' feedback should be included in a discussion about energy security issues. Furthermore, existing governance systems should be studied in more detail to understand how participatory governance works in different countries and how differing degrees of centralization or decentralization of decision-making as well as different regulatory and institutional frameworks shape the process of stakeholder involvement in discussions about energy security issues.

Regarding the guiding principle "transparency," it seems that it is not only connected with the availability of information and its clarity but also with the level of trust in the source of this information. This result also corresponds to the available evidence. When researching public 
opposition to new energy infrastructure, Devine-Wright (2012) investigated the role of place attachments as well as the project-related constructs such as perceived impacts, trust, and procedural justice [23]. Based on surveys from inhabitants in southwest England, he found that perceptions of positive and negative impacts of the project, followed by trust in developer and procedural justice, are identified as major factors influencing public opposition. Cotton and Devine-Wright (2011) studied the discourse among stakeholders and the local community in response to a new power line [63]. They revealed three discourses about procedures for public participation, trust in the transmission system operators, and the need for the project in light of the possibility of centralized or decentralized energy generation. In a comparative study on public beliefs about high-voltage power lines in Norway, Sweden, and the United Kingdom, Aas et al. (2014) used correlation analysis to reveal that the strongest correlation is between acceptance or support of the project and trust in TSO's activities [64]. Trust, therefore, seems to be one of the major factors influencing social support.

Currently there is no common agreement on how to measure either the efficiency of stakeholders' participation methods or the degree of stakeholders' participation that should be reached to make the project successful. A general lack of empirical consideration regarding the quality of participation methods arises from confusion caused by the lack of an appropriate benchmark for the evaluation and comparison of results regarding participatory processes [65]. It can be difficult to evaluate the quality of participation exercises; the evaluation often focuses more on the quality of the process itself rather than on its outcomes. During the last decade, there have been a number of attempts to specify criteria against which the effectiveness of the participatory process can be assessed. However, there are certain limitations to these attempts, and the developed criteria were not assessed in terms of how they could be applied in practice [66].

The evaluation of procedural justice and the organization of the participatory process in BESTGRID clearly show that full engagement with stakeholders has not been achieved. However, we believe that the heterogeneity of public stakeholders and the complexity of the issues impede comprehensive and deep engagement. Despite this, the value of the BESTGRID process has been fully acknowledged by the participating consortium partners as well as by the interviewed stakeholders. The value is mainly driven by the cooperation with organized stakeholders who represent different public interests and contribute different worldviews. Moreover, cooperation with national and local NGOs stimulates project developers to go beyond standard practices and motivates them to make regular improvements to the infrastructure planning process. These reasons, as well as the observations made during the course of the BESTGRID project, lead us to consider that the cooperation between TSOs and project developers more generally needs to be encouraged and facilitated as it has the potential to deliver better projects and more legitimate outcomes.

It is, therefore, essential for policy makers and energy regulators to consider inclusion of participatory and consultation activities in the decision-making process, as well as to provide measures of how these activities can be realized. In particular, we refer to the fact that capacity among NGOs is very limited and often subject to the availability of funds. In the case of BESTGRID, NGOs received funds from the Intelligent Energy Europe program to carry out the tasks allocated to them in the BESTGRID project. Once the project is terminated, these funds will no longer be available and their expertise and time will need to be moved to different issues, where funds can be raised. While some TSOs could be willing to invest resources into an NGO's capacity scheme because of the value they 
bring to the project, this option is considered problematic for a number of reasons. First of all, NGOs need to remain free to follow their own motivations and principles. If funded by TSOs, they could lose credibility and weaken their position in society. Generally, energy regulators will not allow TSOs to recover the costs for financing capacities within NGOs. The ability of securing capacity among key NGO actors will be important for the realization of the desired grid expansion, because organized groups usually form for reasons of opposition and only very seldom to support the infrastructure siting process.

Today public participation is strongly institutionalized and it is assumed that citizens have an opportunity to express their concerns with the help of organized groups, such as NGOs [63]. However, because of current new institutional arrangements, such as governance beyond the state, in reality citizens do not have more opportunities to express their concerns [67]. In several cases of infrastructure siting it is still the same groups of stakeholders, such as experts and decision-makers, with the power and ability to influence the processes according to their interests. If BESTGRID is assessed by using the ladder of Arnstein, it still mainly includes degrees of tokenism and still no trace of citizen power, which is a sign of unequal distribution of power between different groups of stakeholders.

What we have also learned from the BESTGRID process is that there are basic steps that should to be fully addressed in any consultation process. In the case of transmission grids, the "need" is a fundamental discussion point that, complemented with high levels of transparency and information provision, requires attention in the very early stages. The "need" for a new project is always the result of a set of assumptions and visions of the future. These have to be disclosed and efforts should be made to meet the desires of stakeholders to be engaged in the process of shaping assumptions and future scenarios. We have also learned that a stable and robust environmental protection governance framework benefits project developers because it addresses stakeholders' concerns and creates the basis for cooperation with civil society groups. However, in the BESTGRID project, we did not achieve any insight as to how to address those concerns related to the impacts on the landscape caused by infrastructure as well as visibility effects. Addressing these questions will require additional research.

Moreover, use of the term "acceptance" of a project, whose need was identified by policy-makers in cooperation with experts, should be applied with caution. As Batel et al. (2013) [41] pointed out, "acceptance" is often connected with the toleration of something that is inevitable. Other authors $[43,66]$ also argue that this terminology implies a top-down, normative perspective when acceptance from inhabitants is needed only to legitimize a decision or to allow infrastructure construction without protests. Focusing only on acceptance can divert attention away from other aspects of human reasoning such as support, resistance, apathy, etc. BESTGRID showed that sociopolitical acceptance would also involve institutional changes that indeed would open up the possibility for inhabitants to express their opinion about the need for transmission and generation projects. Currently this is carried out in a top-down process and research on social acceptance shows this [29]. This approach hinders the establishment of an innovative renewables-based power supply.

Many different methods for stakeholder participation-going beyond standard practices and legal requirements - were applied during the duration of BESTGRID. However, the most appropriate techniques for public participation are likely to be hybrids of different methods [43]. The BESTGRID approach is the first project to have been constructed around the active cooperation between NGOs and TSOs. It can be considered a good method to address the many challenges that the infrastructure siting process faces today and could be a source of inspiration for future work. 


\section{Acknowledgments}

The work described in this paper was supported by the European Commission in the frame of the Intelligent Energy for Europe program. The paper reflects the results generated by the BESTGRID project and we would like to thank the members of the BESTGRID project, especially Joanne Linnerooth-Bayer from IIASA, Anthony Patt from ETH Zurich, Antina Sanders and Theresa Schneider from the Renewables Grid Initiative, and Rotraud Hänlein from Germanwatch for their feedback, comments, and input. We would like to thank our project partners, the transmission system operators Elia, TenneT, 50Hertz, and National Grid as well as NGOs such as Germanwatch, BirdLife International, IEW, DUH, BBL, NABU, and Natagora. We are also very grateful to several experts and to the inhabitants of communities affected by the pilot projects who found time to participate in stakeholders' interviews as well as the focus group and were generous with their information and recommendations. Any remaining errors of fact or interpretation are those of the authors.

\section{Author Contributions}

Nadejda Komendantova, Marco Vocciante and Antonella Battaglini designed the data collection protocol, collected data and evaluated the results, conducted literature analysis and drafted the article jointly.

\section{Conflicts of Interest}

The authors declare no conflict of interest.

\section{References}

1. Kunreuther, H.; Gupta, S.; Bosetti, V.; Cooke, R.; Dutt V.; Ha-Duong, M.; Held, H.; Llanes-Regueiro, J.; Patt, A.; Shittu, E.; et al. Integrated Risk and Uncertainty Assessment of Climate Change Response Policies. In Climate Change 2014: Mitigation of Climate Change. Contribution of Working Group III to the Fifth Assessment Report of the Intergovernmental Panel on Climate Change; Edenhofer, O., Pichs-Madruga, R., Sokona, Y., Farahani, E., Kadner, S., Seyboth, K., Adler, A., Baum, I., Brunner, S., Eickemeier, P., et al., Eds.; Cambridge University Press: Cambridge, UK; New York, NY, USA, 2014.

2. IPCC. Summary for Policymakers. In Climate Change 2014, Mitigation of Climate Change. Contribution of Working Group III to the Fifth Assessment Report of the Intergovernmental Panel on Climate Change; Edenhofer, O., Pichs-Madruga, R., Sokona, Y., Farahani, E., Kadner, S., Seyboth, K., Adler, A., Baum, I., Brunner, S., Eickemeier, P., et al., Eds.; Cambridge University Press: Cambridge, UK; New York, NY, USA, 2014.

3. Riahi, K.F.; Dentener, D.; Gielen, A.; Grubler, J.; Jewell, Z.; Klimont, V.; Krey, D.; McCollum, S.; Pachauri, S.; Rao, B.; et al. Energy Pathways for Sustainable Development. In GEA (2012): Global Energy Assessment-Toward a Sustainable Future; Cambridge University Press: Cambridge, UK; New York, NY, USA, 2012; The International Institute for Applied Systems Analysis: Laxenburg, Austria, 2012. 
4. European Commission. A Roadmap for moving to a competitive low carbon economy in 2050 . Communication from the Commission to the European Parliament, the Council and the European Economic and Social Committee and the Committee of the regions; European Commission: Brussels, Belgium, 2011.

5. Battaglini, A.; Lilliestam, J.; Haas, A.; Patt, A.G. Development of SuperSmart Grids for a more efficient utilization of electricity from renewable resources. J. Clean. Prod. 2009, 17, 911-918.

6. German Aerospace Center. Trans-Mediterranean Interconnection for Concentrating Solar Power; German Aerospace Center (DLR) Institute of Technical Thermodynamics, Section Systems Analysis and Technology Assessment: Stuttgart, Germany, 2006.

7. Yergin, D. Ensuring Energy Security. Foreign Aff. 2006, 85, 69-82.

8. Ocaña C.; Hariton A. Security of Supply in Electricity Markets. Evidence and Policy Issues; International Energy Agency, OECD/IEA: Paris, France 2002.

9. Ölz, S.; Sims, R.; Kirchner, N. Contribution of Renewables to Energy Security; IEA Information Paper; OECD/IEA: Paris, France, 2007.

10. Kruyt, B.; van Vuuren, D.; de Vries, H.J.M.; Groenenberg, H. Indicators for energy security. Energy Policy 2009, 37, 2166-2181

11. Sovacool, B.; Brown, M. Competing Dimensions of Energy Security: An International Perspective. Annu. Rev. Environ. Resour. 2010, 35, 77-108.

12. TYNDP. 10-Year Network Development Plan 2012; European Network of Transmission Systems Operators for Electricity: Brussels, Belgium, 2012.

13. ENTSO-E. Ten-Year Network Development Plan; European Network of Transmission System Operators for Electricity (ENTSO-E): Brussels, Belgium, 2012.

14. Ackermann, T.; Göran, A.; Söder, L. Distributed generation: A definition. Electr. Power Syst. Res. 2001, 57, 195-204.

15. European Transmission System Operators (ETSO). Overview of the Administrative Procedures for Constructing $110 \mathrm{kV}$ to $400 \mathrm{kV}$ Overhead Lines; ETSO: Brussels, Belgium, 2006.

16. Battaglini, A.; Komendantova, N.; Brtnik, P.; Patt, A. Perception of barriers for expansion of electricity grids in the European Union. Energy Policy 2012, 47, 254-259.

17. Sander, A. From "Decide, Announce, Defend" to "Announce, Discuss, Decide? Suggestions on how to Improve Public Acceptance and Legitimacy for Germany's $380 \mathrm{kV}$ Grid Extension. Master's Thesis, Lund University, Lund, Sweden, September 2011.

18. Schneider, T.; Battaglini, A. Efficiency and Public Acceptance of European Grid Expansion Projects: Lessons Learned across Europe. Renew. Energy Law Policy Rev. 2013, 1/2013, 42-51.

19. Schweizer-Ries, P. Umweltpsychologische Untersuchung der Akzeptanz von Maßnahmen zur Netzintegration Erneuerbarer Energien in der Region Wahle-Mecklar (Niedersachsen und Hessen); Forschungsgruppe Umwelt Psychologie: Magdeburg, Germany, 2010.

20. Kunreuther, H.; Linnerooth-Bayer, J.; Fitzgerald, K. Siting Hazardous Facilities: Lessons from Europe and America; Wharton Risk Management and Decision Processes Center: Philadelphia, PA, USA, 1994.

21. Renewable Grid Initiative. Beyond Public Opposition to Grid Expansion: Achieving Public Acceptance: Transparency, Participation, Benefit Sharing; Renewable Grid Initiative: Brussels, Belgium, 2011. 
22. Cowell, R., Owens, S. Governing space: planning reform and the politics of sustainability. Government Policy 2006, 24, 403-421.

23. Devine-Wright, P. Explaining "NIMBY" Objections to a Power Line: The Role of Personal, Place Attachment and Project-Related Factors. Environ. Behav. 2012, 45, 761-781.

24. Beierle, T.; Cayford, J. Democracy in Practice: Public Participation in Environmental Decisions; RFF Press: Washington, DC, USA, 2002.

25. Inglehart, R. Modernization and Postmodernization: Cultural, Economic and Political Change in 43 Societies; Princeton University Press: Princeton, NJ, USA, 1997.

26. Cohen, J.J.; Reichl, J.; Schmidthaler, M. Re-focusing research efforts on the public acceptance of energy infrastructure: A critical review. Energy 2014, 76, 4-9.

27. Burningham, K.; Barnett, J.; Thrush, D. The Limitations of the NIMBY Concept for Understanding Public Engagement with Renewable Energy Technologies: A Literature Review, Beyond Nimbyism research project Working Paper 1.3. Available online: http://geography. exeter.ac.uk/beyond_nimbyism/deliverables/bn_wp1_3.pdf (accessed on 27 November 2006).

28. Kaldellis, J., Kapsali, M., Kaldelli, E., Katsanou, E. Comparing recent views of public attitude on wind energy, photovoltaic and small hydro applications. Renewable Energy 2013, 52, 197-208.

29. Wolfsink, M. The research agenda on social acceptance of distributed generation in smart grids: Renewable as common pool resources. Renew. Sustain. Energy Rev. 2012, 16, 822-835.

30. Bell, D.; Gray, T.; Haggett, C. The "Social Gap" in Widn Farm Policy Siting Decisions: Explanations and Policy Responses. Environ. Politics 2005, 14, 460-477.

31. Krohn, S.; Damborg, S. On public attitudes towards wind power. Renewable Energy 1999, 16, 954-960.

32. Ek, C. Public acceptance and private attitudes towards "green" electricity: the case of Swedish wind power. Energy Policy 2005, 33, 1677-1689.

33. Devine-Wright, P. Beyond NIMBYism: Towards an integrated framework for understanding public perceptions of wind energy. Wind Energy 2005, 8, 125-139.

34. Wüstenhagen, R.; Wolsink, M.; Bürer, M.J. Social acceptance of renewable energy innovation: An introduction to the concept. Energy Policy 2007, 35, 2683-2691.

35. Barthes, Y.; Mays, C. High Profile and Deep Strategy: Communication and Information Practices in France's Underground Laboratory Siting Process; Technical Note SEGR/98, 18; Institute De Protection Et De Surete Nucleaire: Paris, France, 1998.

36. Batel, S.; Devine-Wright, P. A critical and empirical analysis of the national-local "gap" in public responses to large-scale energy infrastructures. J. Environ. Plan. Manag. 2015, 58, 2015.

37. Media Effects: Advances in Theory and Research, 2nd; Bryant, J., Zillmann, D., Eds.; Lawrence Erlbaum Associates, Inc.: Mahwah, NJ, USA, 2002.

38. Perhac, R. Comparative Risk Assessment: Where Does the Public Fit In? Sci. Technol. Hum. Value 1998, 23, 221-241.

39. Rowe, G.; Frewer, L. Public participation methods: A framework for evaluation. Sci. Technol. Hum. Values Winter 2000, 25, 3-29.

40. Jasanoff, S. The political science of risk perception. Reliab. Eng. Syst. Saf. 1998, 59, 91-99.

41. Batel, S.; Devine-Wright, P.; Tangeland, T. Social acceptance of low carbon energy and associated infrastructures: A critical discussion. Energy Policy 2013, 58, 1-5. 
42. Aitken, M. Why we still don't understand the social aspects of wind power: A critique of key assumptions within the literature. Energy Policy 2010, 38, 1834-1841.

43. Smith, P.; McDonough, M. Beyond Public Participation: Fairness in Natural Resource Decision Making. Soci. Nat. Resour. Int. J. 2001, 14, 239-249.

44. Middendorf, G.; Busch, L. Inquiry for the public good: Democratic participation in agriculture research. Agric. Hum. Values 1997, 14, 45-57.

45. Arnstein, S.R. A Ladder of Citizen Participation. J. Am. Plan. Assoc. 1969, 35, 216-224.

46. Rau, I.; Schweizer-Ries, P.; Hildebrandt, J. The Silver Bullet for the Acceptance of Renewable Energies? In Vulnerability, Risks, and Complexity: Impact of Global Change on Human Habitats; Kabisch, S., Kunath, A., Schweizer-Ries, P., Steinführer, A., Eds.; Gottingen: Hogrefe, Germany, 2012; pp. 177-191.

47. McCallum, David B. and Santos, Susan L. Comparative Risk Analysis for Priority Setting. Human Ecological Risk Assessment J. 1997, 3, 1215-1234.

48. Renewable Grid Initiative. European Grid Declaration on Electricity Network Development and Nature Conservation in Europe; Renewable Grid Initiative: Berlin, Germany, 2011.

49. Rottmann, K. Recommendations on Transparency and Public Participation in the Context of Electricity Transmission Lines; Position Paper; Germanwatch: Bonn, Germany, 2014.

50. Hänlein, R. Public Participation and Transparency in Power Grid Planning. Recommendations from the BESTGRID Project; Germanwatch: Bonn, Germany, 2015.

51. Schneider, T.; Sander, A. European Grid Report: Beyond Public Opposition, Lessons Learned Across Europe; Renewable Grid Initiative: Berlin, Germany, 2012.

52. Shaw, S., Elston, J., Abbott, S. Comparative analysis of health policy implementation: The use of documentary analysis. Policy Studies 2004, 25, 259-266.

53. Yin, R.K. Case Study Research: Design and Methods, 3rd ed.; Sage: Thousand Oaks, CA, USA, 2003.

54. Thomas, G. A typology for the case study in social science following a review of definition, discourse and structure. Qual. Inq. 2011, 17, 511-521.

55. Flyvberg, B.; Holm, M.; Buhl, S. How common and how large are cost overruns in transport infrastructure projects? Transp. Rev. 2003, 23, 71-88.

56. Flyvberg, B. Five Misunderstandings about Case-Study Research. Qual. Inq. 2006, 12, 219.

57. Komendantova, N.; Linnerooth-Bayer, J.; Patt, A. Methodological and theoretical framework mapping commonalities and differences of separate pilot study action plans onto a common framework of actions and guiding principles. Deliverable 2.2, BESTGRID Project, Brussels, 2014. Available online: http://www.bestgrid.eu/uploads/media/D2.2_Common_Methodology_ Framework.pdf (accessed on 31 March 2015).

58. Komendantova, N.; Linnerooth-Bayer, J.; Patt, A. Common Protocol for Data Collection and Recording to Ensure Comparability across Pilot Projects of the Quantified Indicators. Deliverable 2.3, BESTGRID Project, Brussels, 2014. Available online: http://www.bestgrid.eu/uploads/media/ D2.3_Data_Collection_Protocol.pdf (accessed on 24 October 2013).

59. Xavier, R.; Komendantova, N.; Jarbandhan, V.; Nell, D. Participatory Governance in the Transformation of the South African Energy Sector: Critical Success Factors for Environmental Leadership. Clean. Prod. J. 2014, to be submitted. 
60. Porsius, J.; Claassen, L.; Smid, T.; Woudebberg, F.; Timmermans, D. Health responses to a new high-voltage power line route: Design of a quasi-experimental prospective field study in the Netherlands. BMC Public Health 2014, 14, 237.

61. Tempesta, T.; Vecchiato, D.; Girardi, P. The landscape benefits of the burial of high voltage power lines: A study in rural areas of Italy. Landsc. Urban Plan. 2014, 126, 53-64.

62. Elliott, P.; Wadley, D. Coming in Terms with Power Lines. Int. Plan. Stud. 2012, 17, 197-210.

63. Cotton, M.; Divine-Wright, P. Discourses of energy infrastructure development: A Q-method study of electricity transmission line siting in the UK. Environ. Plan. 2011, 43, 942-960.

64. Aas, O.; Devine-Wright, P.; Tangeland, T.; Batel, S. Public beliefs about high-voltage powerlines in Norway, Sweden and the United Kingdom: A comparative survey. Energy Res. Soc. Sci. 2014, 2, 30-37.

65. Lowndes, V.; Pratchett, L.; Stoker, G. Trends in Public Participation: Part 1-Local Government Perspectives. Public Adm. 2001, 79, 205-222.

66. Webler, T. "Right" Discourse on Citizen Participation. An Evaluative Yardstick. In Competence and Fairness in Citizen Participation. Evaluating Models for Environmental Discourse; Renn, O., Webler, T., Wiedermann, P., Eds.; Springer: Dordrecht, The Netherlands; Boston, MA, USA, 1995.

67. Swyngedouw, E. Governance Innovation and the Citizen: The Janus Face of Governance-beyondthe-State. Urban Studies 2005, 42, 1991-2006.

(C) 2015 by the authors; licensee MDPI, Basel, Switzerland. This article is an open access article distributed under the terms and conditions of the Creative Commons Attribution license (http://creativecommons.org/licenses/by/4.0/). 